\title{
EL VIAJE INMIGRATORIO DE FAMILIAS JUDÍAS HACIA CHILE EN EL SIGLO XX
}

The immigratory travel of jewish families toward Chile in the XXth century

\author{
Dr. Mario Matus G. \\ Universidad de Chile \\ mmatus@uchile.cl \\ Chile
}

\section{Resumen}

Este trabajo describe los principales aspectos del viaje inmigratorio de familias judías a Chile y postula que tal viaje estuvo conformado por un conjunto importante de desafíos relativamente comunes. Por otro lado, plantea que estos desafíos tuvieron magnitudes muy diversas dependiendo de la circunstancia específica del contexto histórico y condicionaron vivencias muy variadas. Por último, postula ciertas capacidades que pudieron haber contribuido a amortiguar las considerables dosis de incertidumbre que rodearon cada viaje, y que habrían servido de apoyo desde el momento de la partida hasta el momento de la llegada y la inserción en Chile.

Palabras clave: Inmigración judía - Viaje - Capital social

\begin{abstract}
This paper describes the main aspects of immigration of Jewish families travel to Chile and suggests that such a trip was made by an important group of relatively common challenges. On the other hand, argues that these challenges were very different magnitudes depending on the specific circumstances of the historical context and conditioned experiences varied. Finally, proposes certain capabilities that may have helped cushion the considerable level of uncertainty that surrounded each trip, and would have served as support since the time of departure to the arrival and entry into Chile.
\end{abstract}

Keywords: Jewish inmigration - Travel - Social capital 


\section{Aspectos básicos de la inmigración judía a Chile ${ }^{1}$}

A grandes rasgos, la inmigración judía a Chile podría situarse en dos grandes momentos. En primer término, existió una inmigración muy diseminada y casi imperceptible entre la conquista española y 1895. Durante el período colonial, conversos de origen judío sefardí o descendientes de éstos arribaron al país desde España escapando de la acusación de judaizar. Ya en el período republicano, comenzaron a llegar inmigrantes de Europa del centro y del este, esencialmente súbditos del Imperio Austro-Húngaro, del Imperio Turco y del Imperio Ruso. Debido a estas procedencias, los judíos que ingresaron a Chile luego de su Independencia y hasta 1895 fueron esencialmente ashkenazíes. Más allá de los matices de rigor, lo que caracterizó a estos leves flujos de inmigrantes judíos hasta 1895 fue su carácter encubierto o indocumentado, pues en efecto, ninguno de ellos declaró su condición como judío al ingresar al país.

La segunda gran etapa en la que puede dividirse el proceso de inmigración judía a Chile corresponde al período que se inicia en 1895 y culmina hacia fines de la década de 1950, un poco después de haber finalizado la II Guerra Mundial. Quizás la característica principal de la inmigración judía a Chile en este período sea el hecho de tratarse de flujos más abundantes, más regulares y, especialmente, mejor documentados por los registros y las estadísticas oficiales (Archivo de Extranjería del Ministerio del Interior, Censos de la República). Por otro lado, una buena parte de este flujo -como aquel producido a raíz de los refugiados que escapaban de las atrocidades del régimen nazi y a raíz del fin de la II Guerra Mundial- debió ser claramente connotado como de refugiados judíos, que ya no pudieron esconderse tras los pasaportes de los países en que habían vivido.

Este segundo momento -entre 1895 y fines de la década de 1959- ha legado un mayor número de relatos de viaje. Ello ha llevado a concentrarse en el viaje inmigratorio judío producido en la primera mitad de siglo XX hacia Chile.

Otro aspecto básico a considerar al momento de situar el viaje inmigratorio judío a Chile 
durante este período tiene que ver con la causalidad del viaje y su impacto en la vida de las personas que lo vivieron.

Si consideramos que lo normal es que las personas no deseen cambiarse de país y prefieran continuar sus vidas junto a sus seres queridos en los lugares en que nacieron y se desarrollaron, debemos concluir que aquellos que lo hicieron, se vieron obligados a hacerlo debido a las condiciones del contexto. Desde ese punto de vista, el viaje se ve caracterizado por una fe y una esperanza ciega en que el lugar de llegada ofrecerá mejores posibilidades para vivir en paz y prosperidad. Los economistas usan una fórmula implacable para expresarlo: la gente "vota con los pies", lo que significa que ante la imposibilidad de expresar las aspiraciones de bienestar y de una mejor calidad de vida por medios políticos, normalmente los flujos migratorios expresan muy bien la valoración que las personas hacen de las diferencias relativas entre los países.

De tal modo, el viaje es un puente de experiencias entre las circunstancias vividas en la tierra que se abandona y las esperanzas depositadas en la nueva vida que se desea construir. Pero se trata de un puente marcado por la incertidumbre, por lo desconocido, aunque tales palabras no son necesariamente negativas si las condiciones de salida han sido extremas.

Por ello, antes de medir el grado de incertidumbre contenido en viajes de este tipo, y antes de tratar de hacer una valoración de tal incertidumbre debe tenerse en cuenta que las condiciones que lo envolvían podían diferir en grado sumo. En el caso de los judíos que emigraron a Chile en la primera mitad de siglo XX, el viaje pudo tener motivaciones definibles simplemente como económicas. En otros momentos, se trató de entornos relativamente hostiles para los judíos, como el huir de un deterioro de la convivencia con las poblaciones de acogida, evitar un reclutamiento forzado o escapar de escenarios de guerra, como ocurrió con los trastornos producidos por la I Guerra Mundial. Pero en casos más cercanos en el tiempo - hablamos de la década de 1930 y 1940- se trató de salvar la vida y escapar de las atrocidades nazis, o de dejar atrás países que recibieron a los supervivientes con odiosidad y rechazo. Por consiguiente, cada una de las circunstancias de salida, más o menos dramáticas, más o menos extremas, modeló cuadros de angustia e 
incertidumbre muy distintivos, que en algunos casos podía ser tomada como una posibilidad de renacer a la vida -ante el temor a la muerte- mientras que en otros tendía a ser visto con pesadumbre y resignación. En ello cobraba mucha importancia el estado de seguridad y de bienestar en que quedaban los parientes que se dejaban.

\section{Los desafíos del viaje}

Fuera de los aspectos básicos que lo condicionaron y le imprimieron una impronta más o menos negativa, el viaje siempre estuvo constituido por un número no poco importante de desafíos, algunos tan elevados que pudieron abortarlo en su inicio.

El desafío más inmediato fue conseguir la visa para ingresar al país. Luego debían reunirse los recursos para financiar el viaje. En tercera instancia, debía tomarse en cuenta que la única forma viable para alcanzar tierras americanas desde el viejo continente era a través de la vía marítima, lo que podía implicar ciertos peligros dependiendo de las rutas de tránsito, de los puntos de recalada y de la calidad de las embarcaciones. A eso debían agregarse eventuales restricciones al libre tránsito de personas, que posiblemente podían elevarse en caso de conflicto bélico y aún más cuando se trataba de países con regímenes antisemitas, que podían obligar a la embarcación a regresar. Además, la llegada a un puerto podía requerir posteriores desplazamientos terrestres. En medio del viaje podían suceder muchas cosas, desde un eventual naufragio hasta una denegación de los permisos para concluirlo. En el viaje era posible enfermarse, ocasionales dificultades idiomáticas podían generar problemas, era viable deprimirse, era posible que las pertenencias esenciales fueran robadas, etc. Por último, el éxito del viaje podía medirse inicialmente por la forma en que fue vivido por los propios protagonistas, el modo como lo evocan y los estados de ánimo que les transmite.

Los relatos son bastante reveladores de las dificultades. Algunos de ellos se refieren específicamente a los obstáculos que se debieron vencer para conseguir una visa a Chile, esfuerzo económico y a la vez de cabildeo y de contactos. Rudy Hayman relata cómo debió arreglárselas una vez finalizada la II Guerra Mundial: "Mis padres iniciaron los trámites 
para conseguir una visa de inmigración a Chile para mí. Escriben que hay que tener paciencia, pues es un proceso largo, y todo procedimiento burocrático es extremadamente lento en Chile. Nada menos que dieciséis meses de solicitudes y trámites fueron necesarios para obtener la visa, y ésta es enviada a El Cairo, el consulado más cercano, para estamparla en mi pasaporte inglés."

Pero el cónsul chileno en El Cairo pone obstáculos y dificultades, hasta que finalmente logra su objetivo: vence la visa difícilmente obtenida. Con el desesperado esfuerzo de mis padres se consigue una prórroga, y para mayor seguridad se despacha la visa a Milán. Escribe mi padre: "Tu vida debe estar estampada en tu pasaporte a más tardar en enero de 1948. Todos mis pensamientos giran en torno a lograr que vengas lo más pronto a Chile" (Hayman, 2005, p. 175).

A su vez, Marco Antonio de la Parra, describe el rol esencial jugado por una familia chilena de origen sefardí, para conseguir la visa de Elie Alevy a Chile al finalizar la II Guerra Mundial:“Eran los tiempos de la Guerra Fría. No quería volver a Grecia ni quedarse en Francia. Sabía de Brasil, Argentina y México como tierras de nuevas oportunidades. Conoce, sin embargo, una familia chilena, Assael, del pueblo de su primo, cuyo padre vivía desde los años 20 en Chile. Lo invitan a Chile. Le dicen que ellos le van a sacar un permiso de estadía y trabajo" (Aguilar, 2005, p. 214).

Por supuesto, las posibilidades reales de obtener visa, en muchos casos condicionaron el destino. Un judío italiano, Arrigo Zwillinger, lo relata de este modo: "Cuando salieron las leyes raciales... (en Italia)... mi padre fue a buscar una visa para hacerme partir... mi padre se encargó de eso. Luego fue a Génova, donde pagó algo. Había casos en que la gente pagaba. A la pregunta ¿por qué a Chile?, responde: Porque fue el país que me dio la visa” (Musetti, 2008, p.80). Ester Conforti, otra inmigrante procedente de Italia, revela los montos que podían estar implicados en la obtención de la visa: "Fue un asunto difícil porque era necesario mandar el dinero para obtener la visa. El gobierno, la persona encargada que en Chile se preocupaba de obtener las visas, todo costaba. Y no se podía mandar dinero fuera de Italia. Yo tenía un miedo tremendo y él (Bruno Conforti, su marido) 
había estudiado leyes y fue derecho al fondo del asunto. Tuvimos que viajar con el dinero y el susto a Zürich, en Suiza. Mi marido tenía mied... Yo no lo sé, quizás no era prudente. Si nos sorprendían... había mucho control. Viajamos en tren, nos quedamos un par de semanas en Suiza y de ahí pudimos enviar el dinero. Nos costó 100 dólares por persona. Para nosotros era una cantidad muy grande: éramos 5 personas y enviamos 500 dólares a una persona en Chile para que nos mandara la visa. Evidentemente, era una persona que tenía contactos. Entonces pudimos partir, comprar los pasajes para el viaje en buque” (Musetti, 2008, p. 99).

Cabe señalar, que normalmente el pago para obtener la visa envolvió a funcionarios chilenos y a personas de instituciones judías en Chile en una práctica corrupta y de tráfico de influencias, que llevó a cerrar momentáneamente la puerta a la inmigración judía en 1941. (Nes El, 1987, p. 117).

Una vez obtenida la visa, era necesario reunir el dinero para costear el pasaje por vía marítima. Los casos podían variar de un extremo a otro. Moisés Nahmías, superviviente de Auschwitz y que emigró a Chile desde Grecia, señala que "El dinero para viajar me lo gané haciendo economías. Trabajé en Haifa como cargador en los barcos hasta reunir la plata para los pasajes... Para comer sólo tenía plátanos, nada más. No tenía ni un peso.” (Matus, 1993, p.118). Por el contrario, en casos como los de Ani Luzzato Benedik, de una familia relativamente pudiente que inmigró desde Italia, “(...) no podíamos llevar dinero con nosotros y entonces gastamos todo en el viaje: viajamos en primera clase” (Musetti, 2008, p.104). Algunas familias italianas, como la de Luisa Pontecorboli, cargó un voluminoso equipaje: "Teníamos 56 baúles. Mi mamá traía consigo el piano: se había recibido de pianista y mi abuelo le regaló un piano y ella se lo trajo a Chile. Había conservado la factura y así se lo llevó para allá. Además teníamos libros, todo el ajuar, la Trecanni completa: 56 baúles” (Musetti, 2008, p.100).

Una vivencia muy repetida fue la financiación comunitaria del viaje, como lo relata Saúl Gloger, quien cuando se le consulta ¿vino en barco? Responde: "En vapor hasta Río de Janeiro, de ahí en avión a Chile. El pasaje lo pagó una asociación que ayuda a los judíos 
sobrevivientes. Perón no quiso dar ni para pasajes por Argentina, a los nazis sí los protegió. Perón no daba visa a los judíos para pasar hacia Chile" (Aguilar, 2005. Pp.151-152).

Conseguida la visa para emigrar a Chile y resuelta la financiación del viaje, cabía tener suerte, pues no siempre había disponibilidad de naves, especialmente durante los meses previos e inmediatamente posteriores a la II Guerra Mundial. Rudy Hayman relata las vicisitudes que tuvo que pasar para poder tomar un barco hacia Chile acabada la guerra:

"Luego, pregunté por un barco al Pacífico. "No hay", fue la respuesta. "¿Y a Buenos Aires?" "Inscríbete en la lista de espera”. “Espera? ¿Cuánto tiempo? "Doce a catorce meses". Recurrí entonces al Joint (Comité de Socorros de la Comunidad Judía), una organización que trabajaba con la Cruz Roja y Naciones Unidad, para el transporte y reinserción de refugiados en sus nuevos destinos... Después de un mes de espera, me asignaron un espacio. Era un típico barco de inmigrantes, que había abastecido a las tropas durante la guerra y que ahora cambiaba la carga militar por humana" (Hayman, 2005, p. 175).

Respecto a los peligros que involucraba el viaje, estos podían revelarse mucho antes de tomar un barco hacia Chile. Así lo relata Eva Singer, superviviente húngara de Auchswitz:

“En 1956 estalló la revolución... (Hungría)... y Eva, ya embarazada de su primer hijo, decidió que valía la pena arriesgarse. No sabía nada más de Chile que su ubicación en el mapa y que hablaban español. Una noche de diciembre, a comienzos del invierno, Eva y Tibor escaparon a pie hasta la frontera con Austria. "Sí, otra vez tuve que recorrer kilómetros con frío y nieve", dice Eva, "parece que es lo que me tocó en la vida" (Aguilar, 2005, p.132).

Pero los peligros podían aumentar al iniciarse el trayecto por mar. Esto fue así especialmente cuando estalló la guerra submarina, como lo relata Rudy Hayman: "Cuatro fueron los últimos barcos que partieron desde Italia al Pacífico a fines de 1939. Dos ya estaban en camino; el Augustus... (navío que llevó a la familia del relator a Chile)... fue el 
tercero en salir y el último en arribar; el cuarto fue hundido en alta mar por un submarino alemán" (Hayman, 2005, p. 37). A su vez, como hemos dicho, los judíos podían ser interceptados y retenidos en cualquier puerto de recalada, atendiendo a las complicadas circunstancias de cada país ante los inicios de la guerra. A Ester Conforti, de procedencia italiana, le tocó vivir uno de estos tensos incidentes:

"Nos detuvieron en Marsella y bajaron a todos los varones alemanes, los que en realidad eran judíos escapados del nazismo. Entre ellos, también a mi marido, a Pontecorboli y a Levi, que no eran alemanes. De todas las parejas alemanas, bajaron a los hombres, porque Francia estaba en guerra con Alemania. Entonces, sin hacer distingos si eran judíos o no, bajaron a todos los maridos, por ser alemanes, y por lo tanto, enemigos, y por lo tanto Marsella no podía autorizarlos a continuar. Fue una tragedia. Me recuerdo perfectamente (...) Seguramente, después se dieron cuenta, porque en el pasaporte, a los judíos los alemanes les ponían una “J”, de “judío”. Pero, como eran tan cuadrados: “¡Los alemanes, abajo!; las mujeres se quedaban. Tomaron a todos los hombres. Después los dejaron libres y una o dos naves después, llagaron acá (a Chile)... Entre éstos había incluso un rabino. Ya que huían como judíos, no eran enemigos de Francia, eran perseguidos por Alemania. Fue una conmoción general. Estaban mi hermano, mi primo, los Pontecorboli, los Levi, otro Loewi...” (Musetti, 2008, Pp.104-105).

\section{Vivencia del viaje}

Las vivencias fueron muy variadas. En el caso de las personas que viajaron en un momento distinto a la Shoá la experiencia fue vivida como una aventura incluso alegre, como parece retratarlo Jacques Rodríguez, quien emigró a Chile desde Francia hacia 1930, cuando tenía apenas 16 años:

"En el viaje no encontré ningún judío. Mi compañero de viaje era un venezolano que estudiaba en La Sorbona... No me daba temor viajar porque ya conocía bastantes lugares. Había gente de Turquía que había salido mucho más joven que yo... No me quedé en ningún tramo intermedio, pero en Callao casi pierdo el barco por salir a farrear con una 
mujer. Lo pude alcanzar en alta mar, con una escalera de cuerdas. En el barco, cuando llegué a Antofagasta, una chiquilla mayor que yo, me invitó a irme con ella a Bolivia, donde su padre tenía una fábrica de zapatos. No acepté, claro” (Matus, 1993, p.122).

Un poco antes, Moisés Camhi, que viajaba desde Monastir escapando del servicio militar hacia 1928 cuenta que "El viaje fue cómodo. En mi pieza también estaba Jacobo Hasson, su señora y su hija Ana.

Nosotros íbamos en las literas de arriba. Eran cuatro camarotes. No había privacidad en la pieza, pero el barco contaba con baños cómodos y la comida era maravillosa. Por eso, tengo buenos recuerdos del viaje" (Matus, 1993, p. 123). David Rodrigues Niego y Fortune Fisse viajaron desde Istambul en 1948 y también conservaron imágenes más bien benévolas del viaje:

"Teníamos muchos bultos. No nos podíamos venir en avión y viajábamos en lugares distintos. Yo viajaba con mi hijo y David se acostaba con los hombres. Lo pasamos muy bien. El único problema fue que en Panamá no nos dejaron bajar a los turcos. Los pasajeros que bajaron tuvieron que ir a la comunidad a avisar que había un matrimonio turco que no podía bajar. El barco se quedó en Panamá” (Matus, 1993, p.122).

Incluso en una circunstancia tan terrible como la que se dio durante el Holocausto, algunos judíos italianos adinerados, al verse obligados a gastar todo el dinero que llevaban consigo en el barco, conscientemente buscaron evadir el contexto, como lo relata Ani Luzzano Benedik: "Fue un viaje maravilloso. Recuerdo que pensaba esta será la última de las cosas bellas en mucho tiempo" (Musetti, 2008, p.104). En ese sentido, L, Musetti recalca: "Viajar en primera significaba concederse el lujo de sentirse en un crucero de placer durante un mes, participar de los bailes y de las fiestas organizadas en las suntuosas naves italianas; ilusionarse durante un mes con estar de vacaciones a bordo de unos de los orgullos de la marina mercante italiana y olvidar las penas sufridas en la patria, aliviar momentáneamente el peso de las preocupaciones por los parientes dejados en Italia y por el incierto futuro en un país desconocido" (Musetti, 2008, p.104). 
A pesar de vivir circunstancias muy distintas, Moisés Nahmías, superviviente de Auchswitz, que apenas logró reunir el costo del pasaje, también guardó un buen recuerdo del viaje: "Viajé en el subterráneo (bodega) el barco. Era muy bueno viajar allá. Salía mucho a cubierta. Los tripulantes eran muy buenos, se pasaba bien" (Matus, 1993, p.123).

Pero así como algunos pudieron evadir los problemas del contexto o simplemente vivieron de buena gana las condiciones del periplo, otros cargaban con mayores dosis de impaciencia o de miedo. Marco Antonio de la Parra relata que Elie Alevy, superviviente de Birkenau-Auschwitz, "Se viene a Brasil embarcado en el Julio César, en tercera clase, mezclado, con los inmigrantes napolitanos que se dirigían a América. Tuvo tan malas experiencias con ellos que pagó para que lo subieran a segunda clase. Cuando se ha vivido lo peor no se tolera tan fácilmente nuevas adaptaciones.” (Aguilar, 2005, p. 215).

En cuanto al miedo, el relato de Daisy Barzilai, superviviente de Auschwitz, es revelador:

"Vinimos juntos con mi esposo y una hija de 5 años, Sol. Sólo quedaron amigos en Salónica. Fuimos en avión a Génova, y desde ahí partimos en un barco italiano en un viaje que duró bastante, como tres semanas. Viajábamos en tercera. La gente después de la guerra no tenía ni para comer. El barco se llamaba "El Salto" y realmente era un salto porque saltaba noche y día. Aunque viajamos en tercera, después de haber sufrido tanto en el campo de concentración, para mí todo era agradable, todo era rico. A mi esposo, sin embargo, le hizo mal viajar en barco y estuvo como diez días acostado y no podía comer. Yo tomaba a mi hija, y como sabía hablar italiano, me iba a primera y conversaba con jóvenes italianos que volvían a Argentina. En el cuarto había cuatro camarotes chiquititos, y yo tuve la mala suerte que en camarote encima del mío dormía un nazi que venía a Argentina. De tal manera que venía muy asustada y por eso pasé muy poco en el cuarto. Yo me di cuenta que era nazi por muchas cosas que hablaba. No sabía que nosotros éramos judíos y al hablar se le sentía el odio a los judíos. Yo dormía con mucho miedo. Estaba aterrorizada por todo lo que viví en el Campo. Nadie podría creer todos estos sufrimientos. Afortunadamente él nunca se dio cuenta que éramos judíos porque hablaba griego con mi 
esposo, que tenía cara de griego, y yo hablaba italiano con los pasajeros. Toda la gente pensaba que yo era italiana. Después me tranquilicé al pensar que en el barco había mucha gente de distinta nacionalidad y pensé que no iba a pasar nada. De todas maneras, con esa experiencia, nunca quise decir que era judía” (Matus, 1993, p.122).

Una vivencia muy distinta es la relatada por Rudy Hayman, quien siendo muy joven había combatido contra el Eje en el Norte de África, había estado en el desembarco aliado en Italia y había formado uno de los primeros cuadros de la Haganá, la primera fuerza militar de Israel, e inmigraba a Chile hacia 1948, con todas estas experiencias a cuestas:

"El barco traía grano y carne congelada desde Argentina a una Europa hambrienta, y al regreso transportaba carne viva humana e ilusiones a un continente joven. Tenía sólo una cubierta y abajo cuatro grandes estibas o bodegas para la mercadería. En ellas colocaron literas de tres pisos y, en el centro, cubiertas de madera sobre caballetes, formando mesas gigantes. Doscientas personas por estiba, una para mujeres, tres para hombres. No tenía ni una ventana y la única cubierta servía de terraza para renovar el aire de los pulmones. Ni hablar de baños, mejor no entrar en detalles. Duro fue el viaje, pero nadie se quejó. Todos se sentían privilegiados de estar en camino y dejar atrás dolores y desilusiones. Todos querían rehacer sus vidas en el mundo nuevo y joven, llenos de esperanzas y expectativas" (Hayman, 2005, p.176).

\section{El equipaje del destierro}

Hasta aquí se ha puesto el acento en demostrar que el viaje inmigratorio de personas de origen judío a Chile, tal como otros procesos inmigratorios, cargó con obstáculos comunes: visa, financiación del viaje, oportunidad para hallar nave, superar los peligros del viaje y soportar el rigor del mismo. Por otro lado, hemos podido observar que este conjunto de desafíos tuvo una carga muy distinta según fuera el contexto de lugar y tiempo. Básicamente, la experiencia de los refugiados y supervivientes de la Shoá no admite comparación alguna con la experiencia de los judíos que pudieron inmigrar a Chile antes de la II Guerra Mundial. 
Sintetizando el problema, podría decirse que la relación entre las vivencias extremas del Holocausto y la expectativas futuras limitadas a la supervivencia y a una vida en paz conformaron un escenario de viaje caracterizado por la esperanza, en su sentido más esencial. Una vez se había perdido todo, el viaje sólo podía suponer algún tipo de mejora. No obstante lo anterior, el cuadro psicológico acarreado por un superviviente de la Shoá o refugiado de la guerra tendió a estar caracterizado por un trauma difícil de desarraigar. Por el contrario, las circunstancias menos dramáticas que rodearon el viaje inmigratorio de judíos a Chile antes de la Shoá configuraron un cuadro más complejo. No siempre lo que se dejaba era lo suficientemente adverso como para concederle al viaje una oportunidad de conseguir una vida mejor.

Considerando ambas situaciones, estos viajes inmigratorios configuraron niveles de incertidumbre muy distintos entre sí. Pero abstrayendo estos parámetros de referencia, los desafíos no dejaban de tener algunos puntos en común, que por lo demás también han sido compartidos por emigrantes muy diversos. El desarraigo, las tensiones propias de la empresa del viaje y el shock cultural al llegar son aspectos característicos en todos los procesos migratorios. En ese sentido, se podría decir que los emigrantes han podido administrar el viaje en la medida que han logrado desarrollar ciertas capacidades consideradas actualmente como cruciales.

Las estrategias son muy variadas, pero básicamente consisten en un stock de capital social, es decir, la pertenencia a una red de confianza y de contactos sociales, que permite al emigrante acudir a ayudas externas para resolver los desafíos personales o familiares. De tal modo, la mayor parte de nuestros inmigrantes declaran en sus relatos que acudieron a ayudas para conseguir y pagar su visa, para financiar el costo del pasaje y lograr un cupo en un barco, para insertarse en un grupo que le permitiera defenderse de amenazas y peligros externos a lo largo del viaje, y finalmente, para contar con un techo y una oferta de trabajo al momento de llegar al país receptor. Por cierto, el acceso a este tipo de ayudas es muy común a todo tipo de emigrantes y no puede ser atribuido a ningún grupo étnico, linguiístico o religioso. Uno de los mecanismos más recurridos por un viaje inmigratorio consiste en lo 
que se ha denominado "migración en cadena" o "emigrar con red". Basándose en el trabajo de J.S. y L.D. MacDonald, César Yañez lo ha definido como “(...) el movimiento a través del cual los presuntos emigrantes se enteran de las oportunidades, son provistos de transportes y obtienen su instalación inicial y empleo, por medio de relaciones primarias con emigrantes anteriores". (Yáñez, 1996, p. 169) Por otro lado, Yáñez toma de David Anisi la noción de “(...) seguridad que ofrece la red al trapecista, que en el caso de la emigración reduce los riesgos e incertidumbre implícitas en el abandono del lugar de origen" ${ }^{2}$. Sin duda, no sería correcto siquiera sugerir que estas prácticas son exclusivas de los migrantes judíos. Todo esto tiene mucho que ver con el concepto de Capital Social ${ }^{3}$.

Sin embargo, hay elementos que sugieren que en el caso de poblaciones judías habrían existido ciertas capacidades adicionales, que no son tan frecuentes en todo grupo de emigrantes. En primer término, debemos considerar que los tejidos sociales formados en la historia de la Diáspora son mucho más profundos y complejos que en el caso de otras comunidades. En efecto, según J. Attali, a partir del s. I en adelante, las comunidades de la Diáspora se organizaron en torno a principios críticos para su supervivencia, entre los que se hallaban los siguientes: 1) No confiar más que en los miembros de la comunidad, 2) Permanecer agrupados y 3) Mantener una red cultural, organizacional y comercial que sostuviera la comunicación entre las comunidades. A estos principios fundamentales se superpusieron dos organizaciones centrales en la vida comunitaria: 1) Un Consejo de Notables, encargado de administrar los cementerios, recaudar impuestos para pagar las contribuciones locales, apoyar a pobres y desvalidos y negociar el rescate o liberación de otros judíos, y 2) Un Tribunal Rabínico, también llamado Bet Din, encargado de reglamentar los precios, las remuneraciones, los pesos y medidas, las tarifas de transporte, las comisiones de negocios, de asignar calles a los oficios y de mediar las relaciones entre empleados y empleadores, creando un derecho laboral embrionario" (Attali, 2005, p.83). Sin duda, al momento de la emigración en el siglo XX muchas de estas instituciones habían desaparecido o tenían un alcance mucho más reducido, pero su huella en los comportamientos tendía a permanecer.

En segundo lugar, las comunidades de la Diáspora habían enfatizado el rol de los 
aprendizajes individuales y colectivos, que tiende a asemejarse con el concepto de Capital Humano ${ }^{4}$. En este caso G. Becker distinguió 3 formas de adquisición de conocimientos útiles para la vida: 1) Educación formal (colegio), 2) Educación intra-familiar y 3) Autoaprendizaje. Pues bien, las escuelas de Talmud-Torá de la Diáspora insistían en un aprendizaje intuitivo, en el que la norma o ley debían ser discutidas en todas sus variantes, ampliando en grado significativo sus ámbitos complejos de aplicación. En cuanto a la educación al interior de la familia, los padres hacían especial énfasis en el rigor y la disciplina en el estudio y en el cultivo de cualquier actividad. Junto a los hábitos de estudio, se daba singular importancia a una ética del trabajo, a la responsabilidad y al ahorro, para prevenir emergencias. Por último, el autoaprendizaje enfatizaba el rol insustituible de las indagaciones personales y la convicción de que un problema nunca tiene una única solución y deben explorarse todas las ventajas y desventajas. En su conjunto, el insumo educacional en el mundo judío formó capacidades críticas para el viaje y la adaptación. Se trataba de saberes aplicados de modo perentorio a circunstancias muy extremas. Esto tiene que ver con los aprendizajes colectivos. El Capital Humano judío tiene el apellido de la errancia, de la trashumancia, de que todo arraigo es momentáneo, etéreo. Por otro lado, a diferencia de la disolución de antiguas comunidades judías, la educación judía fue tremendamente potenciada con la irrupción de la Ilustración en el siglo XVIII y la Emancipación de inicios de s. XIX.

Por último, debe considerarse que las comunidades judías de la Diáspora habían desarrollado un denso complejo de normas formales e informales que regulaban el comportamiento de sus miembros. Estas normas, que se aglutinaban en torno al influyente rol de la Ley Judía (Halajá) se transmitían a las generaciones futuras y formaban un verdadero conjunto de regulaciones sociales de primer orden. Esta riqueza normativa ${ }^{5}$, se confundía y conjugaba con aprendizajes y redes sociales transmitidos de generación a generación y se expresaban en una mayor fortaleza relativa para enfrentar situaciones de riesgo o de intensa incertidumbre. Estos principios se reflejaban esencialmente en una práctica muy difundida entre judíos: el respeto a la palabra empeñada como único mecanismo de cumplimiento de los acuerdos, pactos o contratos. 
Nesti Conforti, inmigrante judía italiana lo explica de este modo:

"Los judíos sabemos muy bien que, en todas las ocasiones, de la necesidad se hace virtud. Es algo que viene desde muy atrás. Es una historia muy accidentada. Yo tengo el atavismo latente, aunque sin darme cuenta ...es decir, me doy cuenta de que no podemos absolutamente perder tiempo: desembarquemos aquí y ya veremos lo que hacemos, por ejemplo, cómo distribuir los dineros. Desgraciadamente, es una forma atávica; nos la han inculcado, nos la han hecho entrar a sangre y fuego: estoy segura..." (Musetti, 2008, p.81).

Como señala Lorenza Musetti, el pueblo judío estaba intrínsecamente adaptado.

Aunque hasta ahora ha sido muy poca explorada la integración de estas tres capacidades en las comunidades judías que debieron emigrar en circunstancias a veces extremas durante el siglo $\mathrm{XX}$, es posible proponerlas como una red de resiliencia grupal, entendiendo como tal a una capacidad no sólo individual, sino también colectiva, de sobreponerse a períodos o acontecimientos de intenso dolor emocional o trauma, fortaleciéndose a partir de los mismos. Hablamos de una tenacidad y perseverancia colectiva, grabadas con fuego en las experiencias colectivas de estos emigrantes, que convirtieron la vivencia del viaje en algo muy peculiar en relación a experiencias similares vividas por otros grupos humanos.

\section{Notas}

1 Este acápite reúne los aspectos centrales de la obra: MATUS, Mario.Tradición y Adaptación. Vivencia de los sefaradíes en Chile. Santiago de Chile. Comunidad Israelita Sefaradí de Chile Editores. 
2 Yáñez, C. Saltar con red. La temprana emigración catalana a América, ca. 1830-1870. Madrid. Alianza Editorial, 1996. MacDonald, J.S. y L. D. (1964). Chain Migration, Ethnic Neighborhood and Social Networks. The Milbank Memorial Fund Quarterly, 52, p. 82. Anisi, D. Trabajar con red: un panfleto sobre la crisis. Madrid. Alianza, 1988.

3Putnam, R. Making Democracy Work: Civic Traditions in Modern Italy. Princeton University Press, 1993.

4Becker, G. El capital humano: un análisis teórico y empírico referido fundamentalmente a la educación. Madrid. Alianza, 1983.

5Que Douglass North llamaría Capital Institucional. North, D. Instituciones, cambio institucional y desempeño económico. México, F.C.E, 1993.

\section{Bibliografía}

AGUILAR, M., R. BRODSKY, R. GUMUCIO, R. MERINO, F. MOUAT Y M.A. DE LA PARRA. El asilo contra la opresión. Cinco judíos del Holocausto en Chile. Agnes Bineth, Américo Grunwald, Eva Singer, Saúl Gloger, y Elie Alevy. Santiago de Chile, Editorial Sudamericana, 2005. ANISI, D. Trabajar con red: un panfleto sobre la crisis. Madrid, Alianza, 1988.

ATTALI, J. Los judíos, el mundo y el dinero. Buenos Aires, F.C.E, 2005.

BECKER, G. El capital humano: un análisis teórico y empírico referido fundamentalmente a la educación.Madrid, Alianza, 1983.

BEHN, H., J. OKSENBERG y W. WEIZ. No digas nunca que esta senda es la final. Viena, Mokka, 2009.

COHEN, J. Los judíos en Temuco. 100 años de Historia. El inicio de la comunidad sefaradí en Chile. Santiago de Chile, RIL Editores, 2002.

HAYMAN, R. El tren partió a las 20:30. Memorias de un migrante: desde Berlín hasta Chile, 1938-1948. Santiago de Chile, La Fuente Editores, 2005.

MACDONALD, J.S. y L. D. Chain Migration, Ethnic Neighborhood and Social Networks. 
The Milbank Memorial Fund Quarterly 52, 1964, p. 82.

MATUS, M. Tradición y Adaptación. Vivencia de los Sefaradíes en Chile. Santiago de Chile. Comunidad Israelita Sefaradí de Chile Editores, 1993.

NES-EL, Moshé. Estudios sobre el judaísmo latinoamericano. Buenos Aires - Jerusalem, Ed. Ultra, 1987.

MUSETTI, L. Judíos italianos en Chile, 1939-1947. Santiago de Chile. Centro de Estudios Judaicos. Facultad de Filosofía y Humanidades, Universidad de Chile, 2008.

PUTNAM, R. Making democracy work: civil traditions in modern Italy. New Jersey, Princeton University Press, 1993.

NORTH, D. Instituciones, cambio institucional y desempeño económico. México, F.C.E, 1993.

PUTNAM, R. Making Democracy Work: Civic Traditions in Modern Italy. Princeton University Press, 1993.

YÁÑEZ, C. Saltar con red. La temprana emigración catalana a América, 1830-1870.

Madrid, Alianza Editorial, 1996. 